
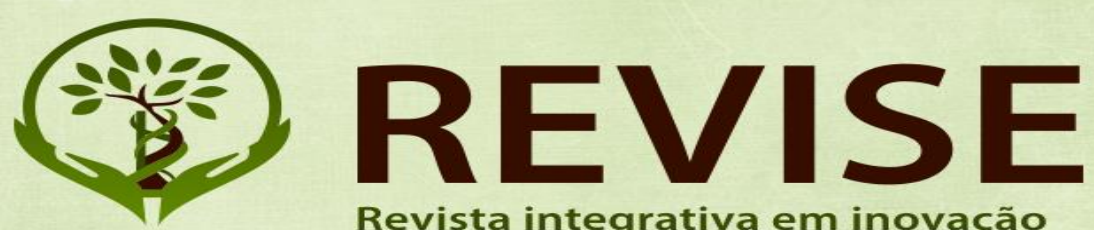

Revista integrativa em inovação tecnológica nas ciências da saúde

\title{
Minicurso: CAPOEIRA E SAÚDE
}

Edmílson José da Hora - Mestre Dennys

Associação de Capoeira Cordão de Prata

\begin{abstract}
RESUMO
O artigo registra os cursos do evento congresso internacional de inovação tecnológica nas ciências da saúde: a sustentabilidade das práticas integrativas a agroecologia, mais especificamente o minicurso: Capoeira e Saúde. O minicurso buscou tratar a capoeira como uma terapia, mais conhecido como capoterapia. O evento aconteceu de 15 a 18 de novembro de 2017 no IFBA SAJ sob a direção da Universidade Federal do Recôncavo da Bahia.

Palavras-chave: PICS. Capoterapia. Saúde. Movimento.
\end{abstract}

\begin{abstract}
The article records the courses of the event international congress on technological innovation in health sciences: the sustainability of integrative practices in agroecology, more specifically the Capoeira e Saúde mini course. The short course sought to treat capoeira as a therapy, better known as capotherapy. The event took place from November 15 to 18, 2017 at IFBA SAJ under the direction of the Federal University of Recôncavo da Bahia.

Keywords: PICS. Capotherapy. Health. Movement
\end{abstract}

Capoeira. Revista Revise, vol. 3, p.1-2. 

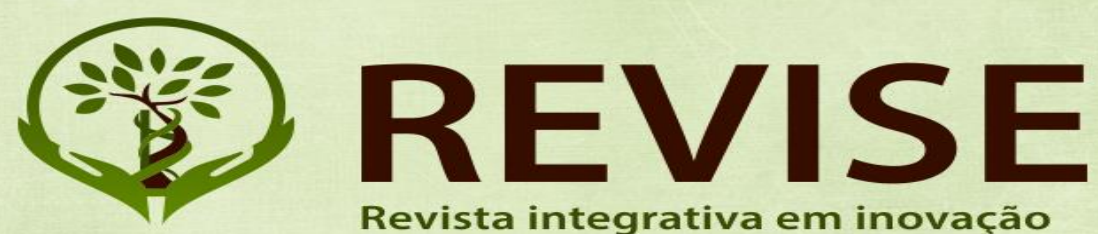
tecnológica nas ciências da saúde

\section{Minicurso}

Podemos afirmar que os jogos de capoeira trazem benefícios; a capoeira possibilita: melhor raciocínio, agilidade, equilíbrio, coordenação motora, reflexos, a visão e a complexibilidade dos movimentos. A prática da capoeira movimenta os membros inferiores e superiores nos dando elasticidade e flexibilidade; potencializa também o condicionamento cardiovascular. A capoeira melhora a estética corporal ao proporcionar uma pele macia, com a transpiração. Os praticantes da capoeira ganham formas estéticas e definição muscular com tonificação do abdômen, glúteos, grade peitoral. Com isso, a as aulas de capoeira proporciona mais saúde completa e rica de movimentos. Contempla também as polifonias da musicalidade que fortalece o corpo e mente. O mau uso da atividade física sem acompanhamento profissional de um mestre de capoeira, sem relatório ou acompanhamentos médicos traz malefícios ao corpo e a mente.

Capoeira. Revista Revise, vol. 3, p.1-2. 